\title{
A importância do exercício de fortalecimento em cadeia cinética fechada na condromalacia patelar
}

\author{
The importance of the exercise of strengthening in kinetic chain closed in patellar condromalacy \\ La importancia del ejercicio de fortalecimiento en cadena cinética cerrada en condomalacia patelar
}

\author{
Bruna Pereira Nagamine \\ ORCID: https://orcid.org/0000-0002-8799-2529 \\ Faculdade Guaraí, Brasil \\ E-mail: brunapnagamine@gmail.com \\ Rildo da Silva Dantas \\ ORCID: https://orcid.org/0000-0001-5684-979X \\ Faculdade Guaraí, Brasil \\ E-mail: rildodantas93@gmail.com \\ Thiago Villagelin Penna Chaves \\ ORCID: https://orcid.org/0000-0001-6304-4383 \\ Faculdade Guaraí, Brasil \\ E-mail: thiagovpc@gmail.com \\ Camila Teixeira de Oliveira Penna Chaves \\ ORCID: https://orcid.org/0000-0002-3008-2591 \\ Faculdade Guaraí, Brasil \\ E-mail: camysto@hotmail.com
}

\begin{abstract}
Resumo
A condromalacia patelar é a degeneração da cartilagem patelar, podendo haver a perda ou a diminuição da rigidez tecidual. Apresentando dor na região anterior da patela ao realizar as atividades de vida diária (AVDs) e ao flexionar e extender a joelho. Os exercícios de fortalecimento muscular em cadeia cinética fechada oferecem um melhor resultado em virtude da funcionalidade e pela facilitação de aplicação e promove o alivio da dor. O objetivo deste artigo é verificar a importância de exercícios de fortalecimento em cadeia cinética fechada na condromalacia patelar, a partir de pesquisas encontradas nas plataformas digitais: Scientific Eletronic Library Online (SciELO) e Google Acadêmico. Conclui-se que os exercícios de fortalecimento muscular em cadeia cinética fechada usadas na Condromalacia Patelar, demonstram em sua maioria, resultados eficazes para reduzir o quadro álgico, fortalecendo toda a musculatura envolvida e proporcionando a melhora da flexibilidade.
\end{abstract}

Palavras-chave: Condromalacia; Fortalecimento muscular; Cadeia cinética fechada.

\begin{abstract}
Abstrat
Patellar chondromalacia is the loss of patellar cartilage, and tissue stiffness may be lost or decreased. Presenting pain in the anterior region of the patella when performing activities of daily living (ADLs) and when flexing and extending the patella. Muscle strengthening exercises in closed kinetic chain offer a better result due to the functionality and the facilitation of application and promotes pain relief. The objective of this article is to verify the importance of strengthening exercises in closed kinetic chain in patellar chondromalacia, based on research found on digital platforms: Scientific Electronic Library Online (SciELO) and Google Scholar. It is concluded that muscular strengthening exercises in closed kinetic chain used in Chondromalicia Patelar, demonstrate, in their majority, effective results to reduce the pain, strengthening the whole musculature involved and providing the improved flexibility.
\end{abstract}

Keywords: Chondromalacia; Muscle strengthening; Exercises in closed kinetic chain.

\section{Resumen}

La condromalacia rotuliana es la degeneración del cartílago rotuliano y la rigidez del tejido se puede perder o disminuir. Presenta dolor en la región anterior de la rótula al realizar actividades de la vida diaria (AVD) y al flexionar y extender la rodilla. Los ejercicios de fortalecimiento muscular en cadena cinética cerrada ofrecen un mejor resultado por la funcionalidad y la facilitación de la aplicación y promueve el alivio del dolor. El objetivo de este artículo es verificar la importancia de los ejercicios de fortalecimiento en cadena cinética cerrada en la condromalacia rotuliana, a partir de investigaciones encontradas en plataformas digitales: Scientific Eletronic Library Online (SciELO) y Google Scholar. Se concluye que los ejercicios de fortalecimiento muscular en cadena cinética cerrada utilizados en 
Condromalacia Patelar, en su mayoría demuestran resultados efectivos para reducir el dolor, fortaleciendo todos los músculos involucrados y proporcionando la mejora de la flexibilidad.

Palabras clave: Condromalacia; Fortalecimiento muscular; Cadena cinética cerrada.

\section{Introdução}

A Condromalácia Patelar é uma patologia que se caracteriza pela degeneração da cartilagem patelar que pode envolver uma ou mais porções da patela, podendo haver a perda ou a diminuição da rigidez do tecido, fazendo surgir fissuras na superfície da mesma. Apresenta uma alta incidência na população, entretanto, sendo mais comum em pacientes do sexo feminino com excesso de peso (Silva, 2012).

Os sintomas estão correlacionados a bloqueio, crepitações, e dor retropatelar. Esses sintomas podem agravar em algumas atividades esportivas que exijam de apoio com carga na flexão do joelho, ou ao subir e descer escadas, pois as compressões entre a patela e o fêmur intensificam (Tavares et al., 2011).

As causas da condromalacia envolvem instabilidade, trauma direto, fratura, subluxação patelar, elevação do ângulo do quadríceps, conhecido com ângulo Q, músculo vasto medial ineficiente, mau alinhamento pós-traumático, síndrome da pressão lateral excessiva e a lesão de ligamento cruzado posterior (Tavares et al., 2011).

Alterações podem decorrer na gênese da condromalácia patelar, entendendo a degeneração superficial dependente da idade, acometendo em pessoas de meia-idade e idosos, e da degeneração basal, que atinge a faixa etária dos adolescentes (Freire et al., 2006).

Os exercícios de fortalecimento na condromalacia patelar em ambos os graus proporcionam maior estabilidade nas articulações envolvidas e mantém o equilíbrio entre os grupos musculares. Os exercícios isométricos são freqüentes na patologia devidos a eficácia para se alcançar o fortalecimento muscular e manter o trofismo dos músculos (Kapandji, 2009).

Segundo Delgado (2003) o Tratamento de Fortalecimento poderia também ser positivamente indicado no préoperatório de indivíduos que devam ser submetidos à cirurgia. Segundo a sua pesquisa, depois de submetidos a cirurgia, $88 \%$ dos indivíduos pertencentes ao grupo que realizou um protocolo de fortalecimento pré cirúrgico para o músculo quadríceps tiveram uma evolução pós cirúrgica excelente, enquanto entre os indivíduos pertencentes ao grupo que não realizou esse trabalho de fortalecimento somente $28 \%$ conseguiu o mesmo feito. E o fortalecimento em cadeia fechada é mais seguro e definitivo através de uma co-contração dos músculos do quadríceps, isquiotibiais, agonistas e antagonistas por proporcionarem uma maior estabilização, independente do grau da patologia. Dessa forma, o presente artigo tem como objetivo verificar os benefícios dos exercícios de fortalecimento em cadeia cinética fechada na patologia de condromalacia patelar.

\section{Metodologia}

O estudo é caracterizado por uma revisão bibliográfica, exploratória e descritiva de abordagem qualitativa. Tendo como base para sua discussão teórica, artigos científicos (Pereira et al., 2018).

O levantamento de dados foi realizado a partir de pesquisas encontradas nas plataformas digitais: Scientific Eletronic Library Online (SciELO) e Google Acadêmico, onde os descritores utilizados foram: condromalacia e fortalecimento muscular. E o objetivo deste artigo é verificar a importância de exercícios de fortalecimento em cadeia cinética fechada na condromalacia patelar,

\section{Resultados e Discussão}

\section{Anatomia do Joelho}

O joelho é uma articulação integra e complexa. É constituída pela extremidade distal do fêmur, extremidade proximal da tíbia e fíbula. Os ligamentos e tendões de músculos que o cruzam, estando constantemente exposta à ação do peso corporal. 
Consequentemente, a sua estabilidade irá depender da relação entre a anatomia óssea, atividade muscular e ligamentar (Castro et al., 2009; Lima et al., 2013).

A articulação fêmoro-patelar se estabelece entre a superfície articular da patela que é constituída pela face patelar e face posterior da patela, que são estabilizadas pelos estabilizadores estáticos e dinâmicos. Onde os estabilizadores dinâmicos são compostos pelos músculos sartório, grácil, semi-tendinoso, semi-membranoso, bíceps femoral, quadríceps femoral - vasto medial (VM), vasto lateral (VL), vasto intermédio e reto femoral. Os retináculos laterais e mediais, da tróclea femoral e da rótula formam os estabilizadores passivo. Se houver uma restrição do movimento, que interfira na amplitude de flexão do joelho pode favorecer a ter uma folga extensora na extensão do joelho e a rotação medial e lateral ocorre em plano horizontal e a extensão e flexão do joelho ocorrem em plano sagital (Kisner 2009).

A articulação do joelho é de forma sinovial que contenta a condição de sustentação de peso, que permite o movimento livre considerável estável. A mobilidade e a estabilidade são efetuadas pela interação dos músculos, movimentos de rolamento e deslizamento nas superfícies articulares e ligamentos (Muller, 2006).

Os músculos extensores e flexores envolvidos são aliados de uma forte estrutura ligamentar que é extremamente resistente, e são responsáveis pelo funcionamento dessa articulação e a articulação do joelho permite uma grande quantidade de movimentos entre a tíbia e o fêmur, além de suportar o peso corporal (Kapandiji, 2009).

Figura 1. Anatomia do Joelho.

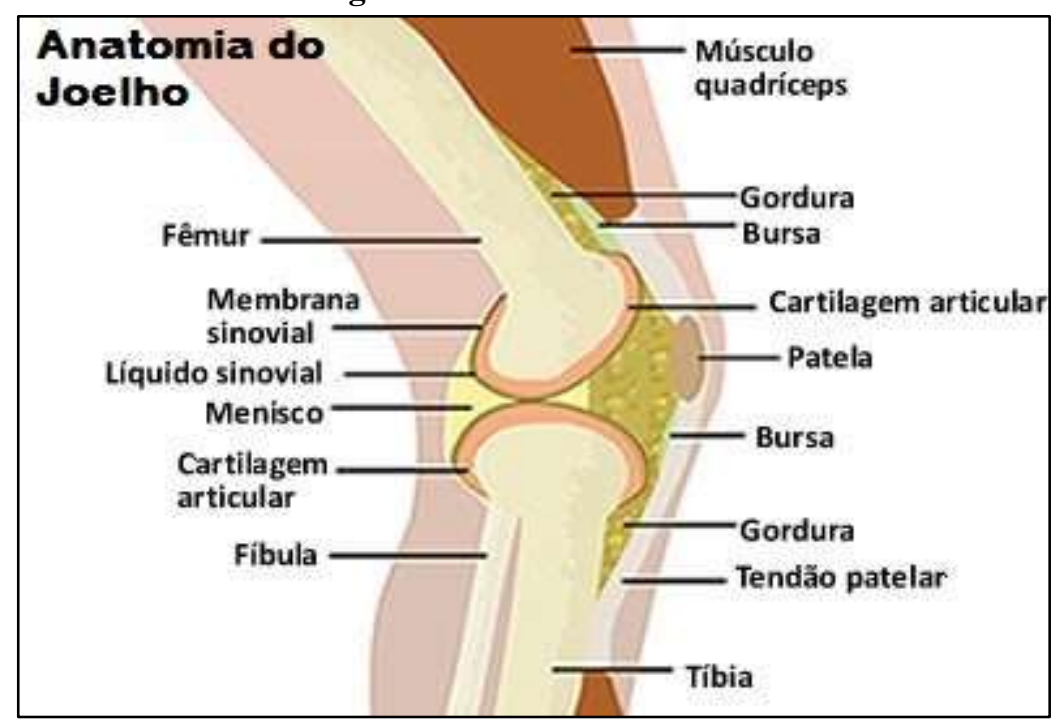

Fonte: https://melhorcomsaude.com.br/seus-joelhos-doem-conheca-causas-e-os-remedios/

\section{Fisiopatologia}

A Condromalacia Patelar é uma patologia que se caracteriza pela degeneração da cartilagem patelar que pode envolver uma ou mais porções da patela, podendo haver a perda ou a diminuição da rigidez do tecido, fazendo surgir fissuras na superfície da mesma. Pode haver dois tipos de alterações: a degeneração basal que atinge os jovens e a degeneração superficial acometendo idosos e pessoas de meia idade. (Silva, 2012). 
Figura 2. Condromalacia Patelar.

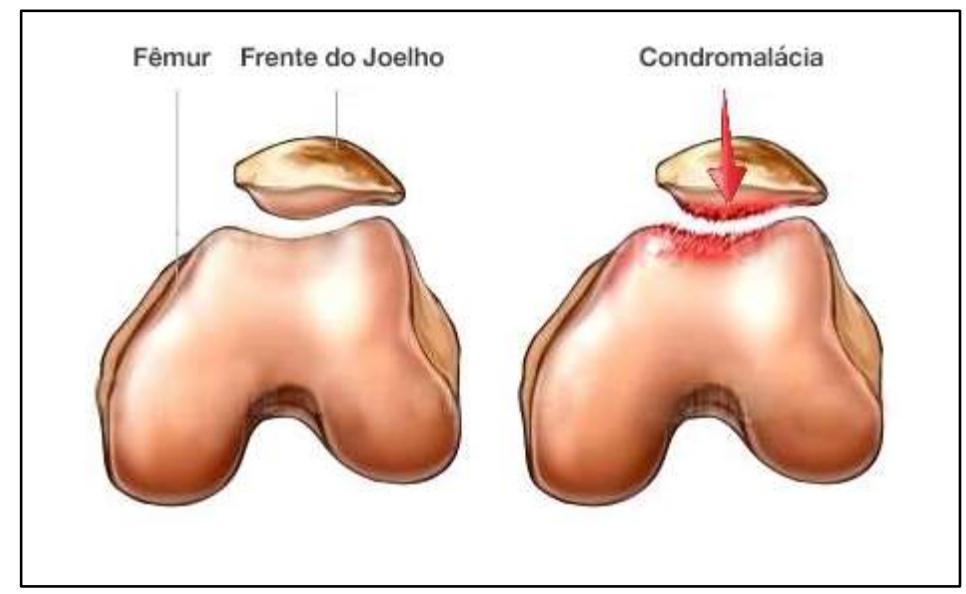

Fonte: https://www.drgustavoarliani.com.br/especialidades/condropatia-da-patela/

Classificação dos graus da patologia descrita por Outerbridge (1961) apud Machado \&Amorin (2005).

\begin{tabular}{|l|l|}
\hline Grau I & Amortecimento da cartilagem e edema \\
\hline Grau II & Fragmentação da cartilagem e fissuras menores que $1.3 \mathrm{~cm}$ de diâmetro \\
\hline Grau III & Fragmentação ou fissuras com $1.3 \mathrm{~cm}$ de diâmetro ou mais \\
\hline Grau VI & Perda de cartilagem e dano ao tecido ósseo subcondral \\
\hline
\end{tabular}

Figura 3. Classificação dos Graus.

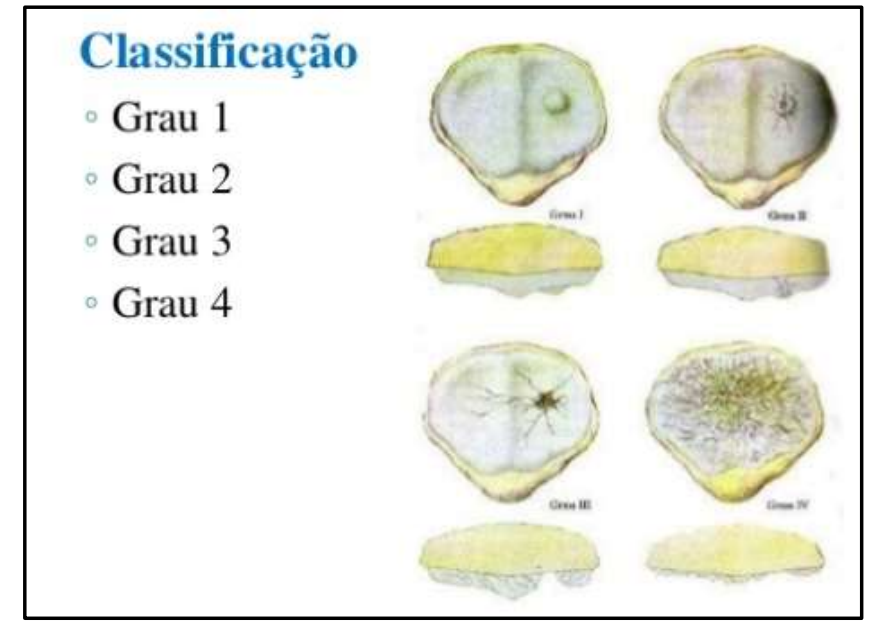

Fonte: https://pt.slideshare.net/TaysBenicio/enfermidades-especficas-do-joelho

As origens da patologia envolvem o aumento do grau Q, instabilidade, mau alinhamento pós-trauma, subluxação da patela, lesão do ligamento cruzado posterior, trauma direto, músculo vasto medial ineficaz e fratura (Tavares et al., 2011).

\section{A Importância dos Exercícios de Fortalecimento em Cadeia Cinética Fechada}

A cadeia cinética é um termo que se utiliza para caracterizar a ativação dos segmentos do membro da perna, de forma sequencial permitindo a transferência de força para a extremidade distal da cadeia, gerando força e estabilização (Davies, 2006). 
A cadeia cinética aberta se distingue da cadeia cinética fechada por ser considerada uma atividade onde o componente distal da extremidade não se encontra fixo, o que proporciona movimentos de segmento isolado dos músculos, ativando poucos mecanoreceptores (Fagan, 2008). Diante disso, os exercícios em cadeia cinética fechada promovem movimentos multiarticulares que são realizados com a extremidade distal fixa, associada com uma descarga de peso gerando uma cocontração dos músculos agonistas e antagonistas, aumentando a estabilidade articular, força de compressão tibiofemoral, diminuição das forças compressivas femoropatelares e menor carga de cisalhamento anterior da tíbia, (Sousa, 2007; Cabral, 2008).

Por meio dos estudos de revisão bibliográfica, notou-se a importância que os exercícios de fortalecimento em cadeia cinética fechada têm sobre a patologia de condromalacia patelar e através dos exercícios de fortalecimento o tratamento busca corrigir o mau alinhamento do membro inferior que é considerado um fator que determina o desenvolvimento da condromalacia patelar, e a anteversão femoral dos desvios no alinhamento patelar secundário, torção tibial externa, joelho valgo e pronação subtalar (Monnerat et al, 2010).

O fortalecimento dos músculos envolvidos proporciona alterações nas formas de condução do SNC (Sistema Nervoso Central), no qual favorece o recrutamento de unidades motoras, estimulando os motoneurônios, melhorando o sincronismo das unidades motoras enquanto se realiza os movimentos, permitindo a redução dos impulsos inibitórios, ampliando a força muscular, trofismo, potência muscular, resistência a fadiga (Kapandji, 2009).

Nos exercícios de cadeia cinética fechada a uma cocontração em pequenos ângulos de flexão dos isquiotibiais diminuindo a translação anterior da tíbia e a rotação interna provocada pelo quadríceps, entretanto, em ângulos acima de $60^{\circ}$ a cocontração faz o deslocamento posterior da tíbia provocando uma rotação externa, aumentando a pressão na patela e devido a cadeia cinética fechada, o centro de gravidade se localiza atrás do joelho, ampliando a força de $0^{\circ}$ até $90^{\circ}$, onde essa força é acompanhada pelo aumento da área de contato até os $60^{\circ}$ depois dessa amplitude a área de contato não aumenta em proporção com a força, pressionando mais a patela. A flexão de joelho a $90^{\circ}$ demonstra maior força de reação femoropatelar, de contato articular e estabilidade femoropatelar, diminuindo o estresse femoropatelar à medida que se aumenta o ângulo de flexão do joelho (Haupentbal, 2006).

Os exercícios fisioterapêuticos de fortalecimento em cadeia cinética fechada usadas na condromalacia patelar demonstraram em sua maioria, resultados eficazes para reduzir o quadro álgico, fortalecendo toda a musculatura envolvida e proporcionando a melhora da flexibilidade. Por tanto, diante do apresentado, recomenda-se que para a elaboração de tratamento na condromalacia patelar deve ser realizado observando os multifatores que levaram ao desenvolvimento da patologia, tais como: alterações morfológicas, atividades praticadas, e, com isso, aumentar a gama de terapias para condromalacia patelar com novos protocolos de tratamento (Santos, 2005).

Em 1995, Steindler trouxe a hipótese de engenharia mecânica de cinemática fechada para estabelecer cinesiologia humana e biomecânica do movimento humano, baseado desses princípios revelaram-se estudos que originaram a cadeia cinética.

Apresentam-se como cadeia cinética fechada (CCF) aqueles exercícios em que o pé ou a mão encontram-se fixos e os movimentos ocorrem de forma previsível, impossibilitando instabilidades e acometimento da estrutura lesada. Há sustentação corporal, mas enfatizam-se que nem todos os exercícios que incluem sustentação são determinados como cadeia cinética fechada (Fagan,2008)

A cadeia cinética fechada envolve exercícios com movimentos multiarticulares que são executados de forma com que a extremidade distal esteja fixa com descarga de peso associada. Esses exercícios geram a co-contração dos músculos agonistas e antagonistas, a fim de proporcionar maior estabilização articular, produzindo ainda menor carga de cisalhamento anterior da tíbia, aumentando a força de compressão tíbio-femoral e diminuindo as forças compressivas femoropatelares próximos do 
movimento de extensão. Alguns estudos retratam a relevância da aplicação dos exercícios de cadeia cinética fechada da perspectiva biomecânica, orientando que se tornam mais seguros por gerarem menos forças e stress, provocando menor riscos as estruturas que estão em processo de recuperação, quando se é comparado com os exercícios em cinética aberta. (Souza, 2007).

Entre os exercícios de cadeia cinética fechada podemos citar: mini agachamentos aumentando significativamente a atividade do quadríceps como um todo, os agachamentos sendo seguro e eficaz por causa do seu efeito estabilizador promovendo uma co-contração dos músculos quadríceps e isquiotibiais é importante diminuir a força de reação e o estresse femoropatelar, considerando que esse exercício deve ser realizado num ângulo de $45^{\circ}$ por permitir mais segurança para a articulação femoropatelar durante um movimento, e o legpress elevar ou reduzir a força de reação femoropatelar em relação ao ângulo de flexão do joelho, para obter um melhor resultado depende da amplitude de movimento da articulação do joelho, de modo que em uma angulação de $60^{\circ}$ e $90^{\circ}$ a força de reação femoropatelar foi maior comparada com $0^{\circ}$ e $30^{\circ}$, gerando uma amplitude de movimento mais confiável (Bevilaqua et al. 2005).

\section{Conclusão}

Neste estudo, foram analisados a importância dos exercícios de fortalecimento em cadeia cinética fechada na condromalacia patelar, uma vez que, os exercícios em cadeia cinética fechada auxiliam na melhora da estabilidade articular, diminui o esforço sobre a articulação, proporcionando o melhoramento da coordenação dos movimentos. Trazendo benefícios para promover o melhoramento dos fatores intrínsecos: desequilíbrio muscular, frouxidão ligamentar, aumento do ângulo $\mathrm{Q}$, subluxação patelar, displasia da patela, displasia troclear, falta de flexibilidade dos ísquios tibiais, pressão lateral excessiva, fraqueza dos músculos abdutores e rotadores laterais do quadril, músculo vasto medial ineficiente, rotação externa da tíbia, gastrocnêmios, sóleos e trato ílio tibial, pé valgo, pé cavo e fatores extrínsecos: hábitos desportivos, sociais, uso excessivo da articulação, tipo e a intensidade da atividade desportiva, trauma direto.

O tema apresentado possui relevância cientifica, pois os exercícios de cadeia cinética fechada vem sendo considerados mais funcionais durante reabilitação de indivíduos que apresentem condromalácia, diante disso, novos estudos são de suma importância para atualizar os benefícios da cadeia cinética fechada diante da patologia abordada.

\section{Referências}

Bevilaqua-Grossi, D. et al. (2005). Avaliação eletromiográfica dos músculos estabilizadores da patela durante exercício isométrico de agachamento em indivíduos com síndrome da dor femoropatelar. Revista Brasileira de Medicina do Esporte, Niterói, 11(3), $159-163$.

Cabral, C. M. N., Melim, A. M. O., Sacco, I. C. N., \& Marques, A. P. (2008). Fisioterapia em pacientes com síndrome fêmoro-patelar: comparação de exercícios em cadeia cinética aberta e fechada. Acta Ortop Bras. 2008;16(3):180-5.

Castro, D. M., \& Vieira, L. C. R. (2009) Joelho: revisão de aspectos pertinentes à Fisioterapia. 2009. Joelho_revisYo_de_aspectos_pertinentes_Y_Fisioterapia.pdf.

Davies, G. J., Heiderscheit, B. C., \& Clark, M. (2006). Reabilitação em cadeia cinética aberta e fechada. In: Ellenbecker TS. Reabilitação dos ligamentos do joelho. São Paulo: Manole; 2006. p. 160-88.

de Sousa, C. O., Ferreira, J. J. A., Medeiros, A. C. L. V., Pereira, R. C., Guedes, D. T., \& de Alencar, J. F. (2007). Atividade eletromiográfica no agachamento nas posições de $40^{\circ}, 60^{\circ}$ e $90^{\circ}$ de flexão do joelho. Rev Bras Med Esporte. 2007;13(5):310-6.

Delgado, L. (2003). Efectividad de la rehabilitación pré-operatoria em la evolución de pacientes operados de condromalacia rotuliana. 2003.54 f. Trabalho para optar pelo título de especialista de primeiro grau em medicina física e reabilitação. Instituto Superior de Ciências Médicas de Havana. Havana.

Fagan, V., \& Delahunt, E. (2008) Patellofemoral pain syndrome: a review on the associated neuromuscular deficits and current treatment options. Br J Sports Med. 2008; 42(10):789-95.

Fagan, V., \& Delahunt, E. (2008). Patellofemoral pain syndrome: a review on the associated neuromuscular deficits and current treatment options. Br J Sports Med. 2008; 42(10):789-95. 
Freire, M. F. de O. et al. (2006). Condromalácia de patela: comparação entre os achados em aparelhos de ressonância magnética de alto e baixo campo magnético. Radiol Bras, 39(3):167-174, 2006.

Haupentbal, A., \& dos Santos, D. P. (2006). Força e contato patelofemoral como fundamentos biomecânicos para reabilitação da síndrome patelofemoral. Fisioter Mov. 2006;19(4):11-6. https://pt.slideshare.net/TaysBenicio/enfermidades-especficas-do-joelho.

Kapandji, I. A. (2009). Fisiologia Articular - Esquemas Comentados de Mecânica Humana. 6.ed. São Paulo: Guanabara Koogan, 2009.

Kisner, C., \& Colby, L. A. (2009). ExerciciosTerapeuticos: Fundamentos e Técnicas. São Paulo; Manole; 5 ed. Brasileira, 2009.

Lima, D. C. L; \& Meija, D. P. M. Método Pilates e sua importância na estabilização da condromalácia patelar: revisão bibliográfica. 9 (4).

Machado, F. A.; \& Amorin, Á. A. (2005). Condromalácia patelar: Aspectos estruturais, moleculares, morfológicos e biomecânicos. 2005. https://melhorcomsaude.com.br/seus-joelhos-doem-conheca-causas-e-os-remedios/>.

Monnerat, E.; Júnio; P. C. N.; Fontenele, G., \& Pereira, J. S. (2010). Abordagem fisioterapeutica em pacientes com condromalacia patelar. Fisioterapia Ser vol. 5 n. 1. 2010.

Muller, T. M. (2006). Estudo da eficácia da hidrocinesioterapia no tratamento da artrose de joelho. 100 p. Trabalho apresentado como requisito para obtenção do título de bacharel em Fisioterapia da Faculdade Assis Gurgacz, Cascavel 2006.

Outerbridge, R. (1961). The etiology of chondromalacia patellae. Br J Bone Joint Surg 1961; 43B:752-7.

Pereira, A. S., et al. (2018). Metodologia da pesquisa científica. UFSM

Santos, A. (2005) Mecanismos biomecânicos implicados na síndrome patelo-femoral e suas relações com a atividade física [Trabalho de conclusão de curso]. São Paulo: Universidade de São Paulo. Escola de Educação Fisica e Esporte; 2005.

Silva, J. M. \& Silva, U. G. S. (2012). Benefícios de um programa de fortalecimento de quadríceps em pacientes acometidos por osteoartrite: uma revisão de literatura. 50 p. Monografia 12 apresentada à Faculdade Nobre de Feira de Santana - BA, como requisito parcial obrigatório da Disciplina de TCC II, para obtenção de título de Bacharel em Fisioterapia. Bahia, 2012.

Sousa, C. O., Ferreira, J. J. A., Medeiros, A. C. L. V., Pereira, R. C., Guedes, D. T., \& de Alencar, J. F. (2007). Atividade eletromiográfica no agachamento nas posições de $40^{\circ}, 60^{\circ}$ e $90^{\circ}$ de flexão do joelho. Rev Bras Med Esporte. 2007;13(5):310-6.

Sousa, C. O. et al. (2007). Atividade eletromiográfica no agachamento nas posições de $40^{\circ}, 60^{\circ}$ e $90^{\circ}$ de flexão do joelho. Ver. Brasileira Med. Esporte, $13(5) 10-6$,

Steindler, A. (1995). Kinesiology of the human body under normal and pathological conditions. ed.: Thomas Springfield, III. 1995

Tavares, G. M. S., Fernandes, A. R. C.; Novo, N. F.; Juliano, Y.; Filho, M. C.; Filho, E. O. F.; Carvalgo, A. F. \& Silva, D. C. (2011) Condromalácia patelar: análise de quatro teste clínicos. ConScientiae Saúde, 10 (1): 77-82, 2011. 